\title{
Effect of comprehensive cardiovascular disease risk management on longitudinal changes in carotid artery intima-media thickness in a community-based prevention clinic
}

Henry G. Cheng ${ }^{1}$, Birju S. Patel ${ }^{1}$, Seth S. Martin ${ }^{1}$, Michael Blaha ${ }^{1}$, Amy Doneen ${ }^{2}$, Brad Bale², Steven R. Jones ${ }^{1}$

${ }^{1}$ The Johns Hopkins Ciccarone Center for the Prevention of Heart Disease, Baltimore, USA
${ }^{2}$ Heart Attack and Stroke Prevention Center, Spokane, USA

Submitted: 25 April 2015

Accepted: 11 May 2015

Arch Med Sci 2016; 12, 4: 728-735

DOI: $10.5114 /$ aoms.2016.60955

Copyright $\odot 2016$ Termedia \& Banach

\section{Abstract}

Introduction: The aim of the study was to examine changes in carotid intima-media thickness (CIMT) and carotid plaque morphology in patients receiving multifactorial cardiovascular disease (CVD) risk factor management in a community-based prevention clinic. Quantitative changes in CIMT and qualitative changes in carotid plaque morphology may be measured non-invasively by ultrasound.

Material and methods: This is a retrospective study on a cohort of $324 \mathrm{pa}$ tients who received multifactorial cardiovascular risk reduction treatment at a community prevention clinic. All patients received lipid-lowering medications (statin, niacin, and/or ezetimibe) and lifestyle modification. All patients underwent at least one follow-up CIMT measurement after starting their regimen. Annual biomarker, CIMT, and plaque measurements were analyzed for associations with CVD risk reduction treatment.

Results: Median time to last CIMT was 3.0 years. Compared to baseline, follow-up analysis of all treatment groups at 2 years showed a $52.7 \%$ decrease in max CIMT, a 3.0\% decrease in mean CIMT, and an $87.0 \%$ decrease in the difference between max and mean CIMT $(p<0.001)$. Plaque composition changes occurred, including a decrease in lipid-rich plaques of $78.4 \%$ within the first 2 years $(p<0.001)$. After the first 2 years, CIMT and lipid-rich plaques continued to decline at reduced rates.

Conclusions: In a cohort of patients receiving comprehensive CVD risk reduction therapy, delipidation of subclinical carotid plaque and reductions in CIMT predominantly occurred within 2 years, and correlated with changes in traditional biomarkers. These observations, generated from existing clinical data, provide unique insight into the longitudinal on-treatment changes in carotid plaque.

Key words: carotid intima-media thickness, cardiovascular disease, vascular disease, lipid, cholesterol, statin.

\section{Introduction}

The natural progression of atherosclerotic lesions has been described in many in-vitro and in-vivo studies. Studies have shown that changes in arterial intima-media thickness precede the formation of atherosclerotic plaques $[1,2]$. These intima-media changes are known as subclinical

\author{
Corresponding author: \\ Steven R. Jones MD \\ Ciccarone Center for the \\ Prevention of Heart Disease \\ Johns Hopkins Hospital \\ 1800 Orleans Street \\ Zayed $7125 \mathrm{U}$ \\ Baltimore, MD 21287, USA \\ Phone: 410-502-9352 \\ Fax: 443-287-3180 \\ E-mail: sjones64@jhmi.edu
}


atherosclerosis and can occur early in life without immediate clinical consequences. Non-invasive imaging modalities such as high-resolution magnetic resonance imaging (MRI), computed tomography (CT), and B-mode ultrasonography have been used to study longitudinal changes in atherosclerotic lesions and plaque morphology [3-5].

Carotid intima-media thickness (CIMT) measured by B-mode ultrasonography is a potentially useful non-invasive method of detecting subclinical atherosclerosis [6-9]. Compared to CT and $\mathrm{MRI}, \mathrm{B}$-mode ultrasound offers a low-cost and informative research tool, without ionizing radiation, for analyzing plaque composition and monitoring changes in its lipid content $[5,10]$. In particular, vulnerable plaques, which are soft and lipid-rich, can be identified on ultrasound by their echo-lucent appearance [5, 6]. Therefore, ultrasonography provides a non-invasive method of studying subclinical atherosclerosis and vulnerable plaque in response to comprehensive interventions. However, there are certain limitations to the use of CIMT in the clinical setting. Despite earlier supportive studies, recent meta-analyses question the value of CIMT as an additional predictor of cardiovascular disease (CVD) risk [11-20]. It received a class III recommendation from the 2013 ACC/AHA lipid guidelines and is not recommended for use as a clinical marker for CVD risk [21]. As a research tool, ultrasonography provides a non-invasive and cost-effective method of changes in plaque morphology and CIMT.

Lipid-modifying therapy helps form the core of modern clinical interventions to alter progression of atherosclerotic lesions. However, combination lipid therapy is controversial as several clinical trials have had mixed results (VA-HIT, HATS, and Atherothrombosis Intervention in Metabolic Syndrome with Low HDL/High Triglyceride and Impact on Global Health Outcomes (AIM-HIGH)) [22-24]. The difference in outcomes may be explained in part by the variable effects of lipid-lowering therapies on subclinical atherosclerosis and differences in the populations studied. The direct effect of statins and niacin on subclinical atherosclerosis was investigated by several CIMT studies, which found that in low-intermediate risk individuals, statins and niacin were effective in slowing or reversing CIMT progression [25-31]. Aggressive short-term statin therapy has also been shown to promote delipidation and stabilization of vulnerable plaque [32, 33]. These favorable changes in plaque morphology were observed using high-resolution optical coherence tomography and integrated backscatter intravascular ultrasound imaging [34].

Longitudinal ultrasound CIMT and plaque morphology investigation offers a non-invasive and effective method to examine this progression. The goal of this retrospective study is to evalu- ate changes in CIMT and plaque morphology in a community cohort of patients receiving comprehensive CVD risk factor management.

\section{Material and methods}

\section{Demographics}

The study is a retrospective cohort of $324 \mathrm{pa}$ tients participating in a comprehensive CVD risk factor management program from 2003 to 2008 in a community-based primary care clinic in the state of Washington. Out of 448 patients in this clinic (Spokane, Washington), 324 elected to participate in this program. There were no eligibility criteria, and patients were not stratified based on CVD risk. All participants underwent baseline and annual physical and laboratory examinations and CIMT scans. This analysis was based on available data collected from program participants. The primary data collection team received institutional review board exemption from the Texas Tech University Health Sciences Center. The data analysis team received institutional review board exemption from the Johns Hopkins School of Medicine. Informed consent was not obtained from study participants for their clinical records to be used in this study. Patient records were anonymized and de-identified prior to analysis.

\section{Treatment strategy}

All patients received extensive behavioral, dietary and lifestyle counseling in keeping with accepted guideline practice $[35,36]$. Clinicians reviewed laboratory data and CIMT imaging, and treated patients with statin, statin plus niacin, statin plus ezetimibe, or statin plus niacin and ezetimibe. Statin-intolerant patients were treated with ezetimibe plus niacin [37]. Retrospective grouping was based on their medication treatment (Table I). Additional therapy with fibrates, bile acid sequestrants, and fish oils was also used as needed to achieve the more aggressive National Cholesterol Education Program (NCEP) ATP III lipid goals. Patients with a history of coronary artery disease (CAD) and/or hypertension were treated with standard low-dose aspirin $81 \mathrm{mg}$, angiotensin-converting enzyme inhibitor (ACEi), angiotensin receptor blocker, $\beta$-blocker, diuretic, renin inhibitor, and/or clopidogrel as indicated. Patients with newly diagnosed insulin resistance, metabolic syndrome, and diabetes mellitus were started on oral insulin sensitizing agents, primarily metformin and thiazolidinediones.

\section{Clinical and laboratory data}

Baseline data included age, sex, height, weight, hemoglobin $A_{1 c}\left(H b A_{1 c}\right)$, high sensitivity C-reactive 
Henry G. Cheng, Birju S. Patel, Seth S. Martin, Michael Blaha, Amy Doneen, Brad Bale, Steven R. Jones

Table I. Demographic characteristics and medication usage by treatment group at baseline

\begin{tabular}{|c|c|c|c|c|c|c|c|c|}
\hline Parameter & Statin & $\begin{array}{c}\text { Statin } \\
\text { plus niacin }\end{array}$ & $\begin{array}{c}\text { Statin } \\
\text { plus } \\
\text { ezetimibe }\end{array}$ & $\begin{array}{c}\text { Statin } \\
\text { plus niacin } \\
\text { and } \\
\text { ezetimibe }\end{array}$ & $\begin{array}{l}\text { Niacin } \\
\text { only }\end{array}$ & $\begin{array}{l}\text { Ezetimibe } \\
\text { only }\end{array}$ & All & $P$-value \\
\hline$N(\%)$ & $62(14)$ & $170(38)$ & $17(4)$ & $55(12)$ & $17(4)$ & $3(1)$ & $324(100)$ & \\
\hline Age, mean \pm SD & $56 \pm 11$ & $56 \pm 9$ & $54 \pm 9$ & $56 \pm 9$ & $50 \pm 13$ & $61 \pm 4$ & $56 \pm 10$ & 0.129 \\
\hline Female, $n(\%)$ & $29(48)$ & $61(36)$ & $10(59)$ & $17(31)$ & $7(41)$ & $2(67)$ & $126(39)$ & 0.169 \\
\hline CAD, $n(\%)$ & $0(0)$ & $20(12)$ & $3(21)$ & $16(31)$ & $1(7)$ & $0(0)$ & $40(13)$ & $<0.001$ \\
\hline Diabetes, $n$ (\%) & $0(0)$ & $7(5)$ & $2(15)$ & $5(10)$ & $0(0)$ & $0(0)$ & $14(5)$ & 0.101 \\
\hline Smoker, $n$ (\%) & $18(31)$ & $50(30)$ & $7(44)$ & $21(38)$ & $3(20)$ & $0(0)$ & $99(32)$ & 0.451 \\
\hline $\begin{array}{l}\text { Hemoglobin } A_{1 c^{\prime}} \\
\text { mean } \pm S D\end{array}$ & $5.6 \pm 0.4$ & $5.6 \pm 0.6$ & $5.7 \pm 0.5$ & $5.8 \pm 0.6$ & $5.2 \pm 0.4$ & $5.4 \pm 0$ & $5.5 \pm 0.7$ & 0.103 \\
\hline $\begin{array}{l}\text { hs-CRP, } \\
\text { median (IQR) }\end{array}$ & $\begin{array}{c}1.7 \\
(0.6-2.6)\end{array}$ & $\begin{array}{c}1.1 \\
(0.6-2.2)\end{array}$ & $\begin{array}{c}1.0 \\
(0.4-1.8)\end{array}$ & $\begin{array}{c}0.6 \\
(0.5-1.6)\end{array}$ & $\begin{array}{c}1.5 \\
(0.8-2.6)\end{array}$ & $\begin{array}{c}1.5 \\
(0.5-2.5)\end{array}$ & $\begin{array}{c}1.1 \\
(0.5-2.1)\end{array}$ & 0.543 \\
\hline ACEi use, $n(\%)$ & $19(31)$ & $63(37)$ & $7(41)$ & $24(44)$ & $6(35)$ & $2(67)$ & $121(37)$ & 0.644 \\
\hline
\end{tabular}

protein (CRP), and history of CAD, diabetes, or cigarette smoking. Body mass index (BMI) was not routinely measured, and baseline insulin use was not available. Blood pressure measurements and laboratory lipid samples were collected within 6 months of the annual CIMT scan and annually thereafter. Total cholesterol, high-density lipoprotein cholesterol (HDL-C), and triglycerides were directly measured. Non-high-density lipoprotein cholesterol (non-HDL-C) was calculated as the difference between total cholesterol and HDL-C, while estimated low-density lipoprotein cholesterol (LDL-C) was calculated using the Friedewald equation [38]. Baseline $\mathrm{HbA}_{1 \mathrm{c}}$ was collected for all study participants. During the 5-year follow-up, $1131 \mathrm{HbA}_{1 \mathrm{c}}$ measurements were obtained out of the 1548 follow-up data points. Baseline high-sensitivity C-reactive protein (hs-CRP) was collected for 471 out of 571 study participants. During the 5-year follow-up, 1303 hs-CRP measurements were obtained out of the 1548 follow-up data points.

\section{B-mode ultrasound imaging}

Certified sonographers at CardioRisk laboratories (South Jordan, UT) performed all annual CIMT scans. CIMT examinations were performed using Sonosite Titan systems equipped with high-resolution B-mode ultrasound with 10-5 MHz, 38-mm linear array transducers (Sonosite Inc, Bothell, WA).

CIMT measurements were obtained using well-defined anatomic markers in the distal $1 \mathrm{~cm}$ of the common carotid artery, the carotid bifurcation, and the proximal $1 \mathrm{~cm}$ of the internal carotid artery [39]. On average, 800 measurements were made at each anatomic carotid site using edge-detection software included with the Sonosite Titan systems. Mean CIMT was the average of all measurements, and max CIMT was the average of the 6 thickest CIMT measurements (including regions with plaque). Carotid plaque was defined as a focal lesion at least $1.3 \mathrm{~mm}$ at its thickest point. Plaques were classified into three echo-density categories representing lipid-rich (echo-lucent), heterogeneous, and calcified (echodense) plaque. Plaque burden was the sum of the maximum thickness in each of the three measurement sites bilaterally.

\section{Data collection}

Research assistants collected data from clinic charts and removed patient identifiers. A data spreadsheet was generated, and a separate data analysis team reviewed the data to ensure integrity. Any missing or mistyped values were flagged and sent back to the data collection team for reexamination. After corrections were made, the database was locked for analysis.

\section{Data analysis}

Patients were retrospectively categorized into lipid treatment groups: statin only, niacin only, ezetimibe only, statin plus niacin, statin plus ezetimibe, statin plus niacin and ezetimibe. The dates of the annual CIMT study served as the primary analysis time point, and clinical and laboratory data obtained within 6 months of that CIMT measurement were attributed to that date.

\section{Statistical analysis}

We examined the outcome measures of mean and max CIMT and plaque composition. Statistical analyses were performed using ANOVA, $\chi^{2}$ test, Fisher's exact, or median test, with $p$-values gen- 
erated by the Wald test as appropriate. Analyses were performed on mean, max, and max minus mean (max-mean) CIMT, and plaque type (soft, heterogeneous and calcified). Changes in CIMT were evaluated using multilevel mixed-effects linear or logistic regression models with a patient-level random intercept. Patients lost to follow-up were censored at the last CIMT scan and were not adjusted for missing data bias.

\section{Results}

\section{Patient baseline results}

The study population included 324 Caucasian patients with at least two CIMT scans. Baseline demographic comparisons are shown in Table I. Briefly, the study population had a mean age of 55 years, $39 \%$ were female, $13 \%$ had CAD, $5 \%$ had diabetes, and $32 \%$ were current or former smokers. The median time to the last CIMT was 3.0 years with a follow-up of 280 (86\%), 234 (72\%), $167(52 \%), 85$ (26\%), and $20(6 \%)$ patients at each of the first 5 years (Table II).

\section{Treatment groups}

Patients received comprehensive CVD risk intervention including diet and physical activity counseling and pharmacotherapy. Within the first year, pharmacotherapy was significantly increased. Statin use increased from $46 \%$ to $87 \%$, niacin use from $16 \%$ to $68 \%$, ezetimibe use from $5 \%$ to $15 \%$, and ACEi use from $36 \%$ to $77 \%$ (Figure 1). Baseline treatment group categorizations are shown in Table I.

\section{Lipid, $\mathrm{HbA}_{1 \mathrm{c}}$, hs-CRP, and blood pressure changes}

There were statistically significant improvements in lipid parameters and systolic blood pressure during the first year of treatment, with stable trends afterwards (Table II). LDL-C decreased by $25 \%$, non-HDL-C decreased by $25 \%$, triglycerides decreased by $31 \%$, HDL-C increased by $6 \%$, and systolic blood pressure decreased by $5 \%$ (Table II, Figure 2). The mean and median $\mathrm{HbA}_{1 c}$ value at baseline was $5.5 \%$, with a standard deviation of $0.7 \%$, interquartile range of $5.2 \%$ to $5.7 \%$, and total range of $4.3 \%$ to $10.8 \%$. There was not a significant association between $\mathrm{HbA}_{1 \mathrm{c}}$ and mean CIMT in a mixed model analysis over time. Mean hs-CRP at baseline was $1.1 \mathrm{mg} / \mathrm{l}$, with a standard deviation of $2.3 \mathrm{mg} / \mathrm{l}$, interquartile range of $0.5 \mathrm{mg} / \mathrm{l}$ to $2.1 \mathrm{mg} / \mathrm{l}$, and total range of $0.1 \mathrm{mg} / \mathrm{l}$ to $15.7 \mathrm{mg} / \mathrm{l}$. There was not a significant association between hs-CRP and mean CIMT in a mixed model analysis over time.

\section{CIMT findings}

Statistically significant changes in CIMT and plaque composition occurred across all treatment groups (Figure 3). There was no statistically significant difference in CIMT between treatment groups. Average max CIMT at baseline was $1.86 \mathrm{~mm}$, average mean CIMT was $0.77 \mathrm{~mm}$, and average maxmean CIMT was $1.08 \mathrm{~mm}$. After 1 year, max CIMT was $1.31 \mathrm{~mm}$ (30\% regression), average mean CIMT was $0.73 \mathrm{~mm}$ ( $5 \%$ regression), and maxmean CIMT was $0.57 \mathrm{~mm}$ (47\% regression), $p<$ 0.001 . After 2 years, max CIMT was $0.88 \mathrm{~mm}$ (52\% regression year-on-year) and max-mean CIMT was $0.14 \mathrm{~mm}$ (87\% regression year-on-year), $p<0.001$ (Table III). Mean CIMT continued to remain stable between 0.73 and $0.78 \mathrm{~mm}$.

Lipid-rich plaque, defined as echolucent plaque on ultrasonography, decreased by $50 \%$ the first year and $56 \%$ the second year, $p<0.001$. There was a $36 \%$ increase in heterogeneous plaque and a $43 \%$ increase in calcified plaque after the first year $(p<0.001)$. There was no significant change in the amount of detectable plaque after the first year of starting treatment ( $p=0.076)$ (Table III).

Table II. Modifiable clinical risk factors over follow-up

\begin{tabular}{|lcccccccc|}
\hline Parameter & \multicolumn{9}{c}{ Year } & $\begin{array}{c}\text { P-value } \\
\text { (first year) }\end{array}$ & $\begin{array}{c}\text { P-value (after } \\
\text { first year) }\end{array}$ \\
\cline { 2 - 7 } & $\mathbf{0}$ & $\mathbf{1}$ & $\mathbf{2}$ & $\mathbf{3}$ & $\mathbf{4}$ & $\mathbf{5}$ & & \\
\hline N (\%) & 324 & 280 & 234 & 167 & 85 & 20 & & \\
& $(100)$ & $(86)$ & $(72)$ & $(52)$ & $(26)$ & $(6)$ & & 0.835 \\
\hline Non-HDL-C, mean $\pm \mathrm{SD}$ & 143 & 107 & 106 & 105 & 102 & 102 & $<0.001$ & \\
[mg/dl] & \pm 41 & \pm 33 & \pm 29 & \pm 32 & \pm 31 & \pm 29 & & 0.904 \\
\hline LDL-C, mean \pm SD [mg/dl] & 118 & 89 & 89 & 88 & 87 & 87 & $<0.001$ & \\
& \pm 36 & \pm 28 & \pm 25 & \pm 27 & \pm 26 & \pm 26 & & 0.001 \\
\hline HDL-C, mean \pm SD [mg/dl] & 53 & 56 & 57 & 58 & 61 & 56 & 0.004 & \\
& \pm 17 & \pm 18 & \pm 17 & \pm 17 & \pm 17 & \pm 17 & & 0.004 \\
\hline Triglycerides, mean \pm SD & 128 & 88 & 89 & 83 & 75 & 77 & $<0.001$ & \\
[mg/dl] & \pm 78 & \pm 49 & \pm 54 & \pm 51 & \pm 46 & \pm 36 & & 0.063 \\
\hline Systolic blood pressure, & 124 & 118 & 119 & 116 & 114 & 116 & $<0.001$ & \\
mean \pm SD [mm Hg] & \pm 15 & \pm 13 & \pm 13 & \pm 14 & \pm 14 & \pm 13 & & \\
\hline
\end{tabular}



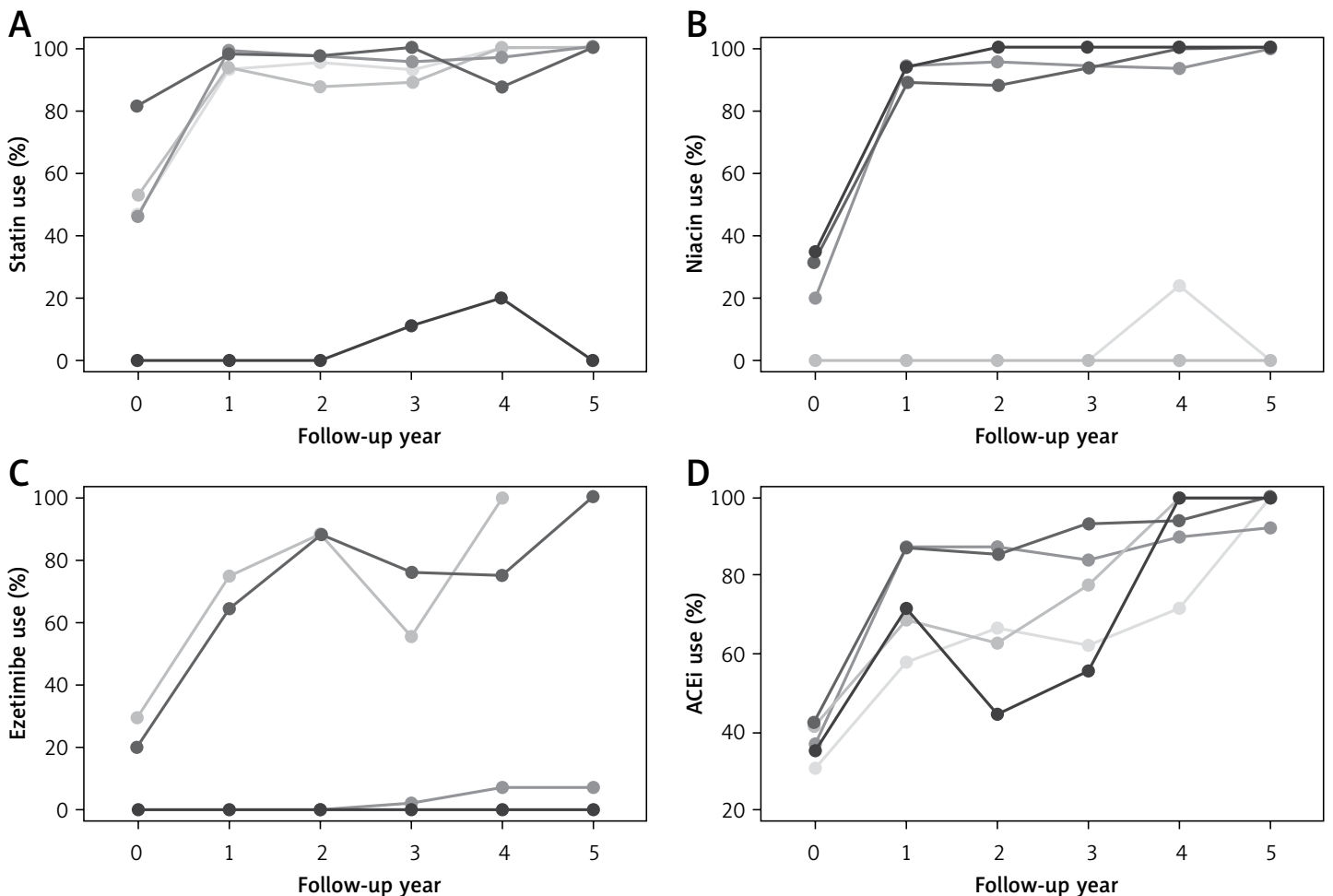

$\approx$ Statin $\approx$ Statin plus niacin $\quad$ Statin plus ezetimibe $\quad$ Statin plus niacin and ezetimibe

Figure 1. Prevalence of use of various pharmacologic therapies by year of follow-up

A

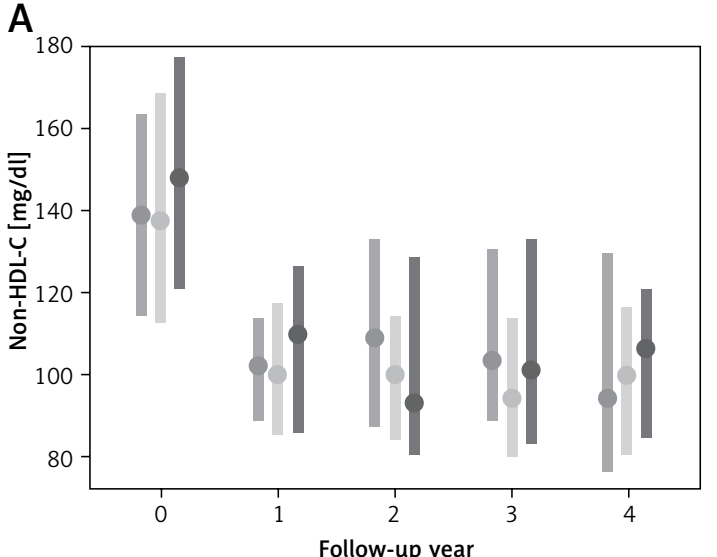

C

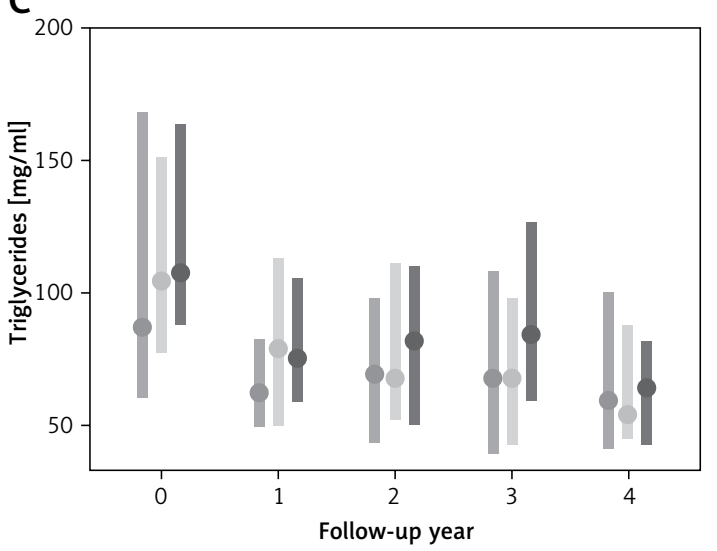

Statin Statin plus niacin
B

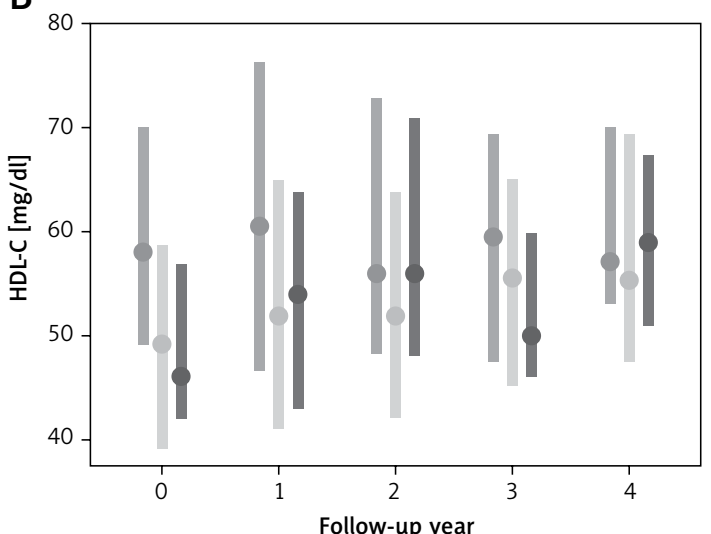

D

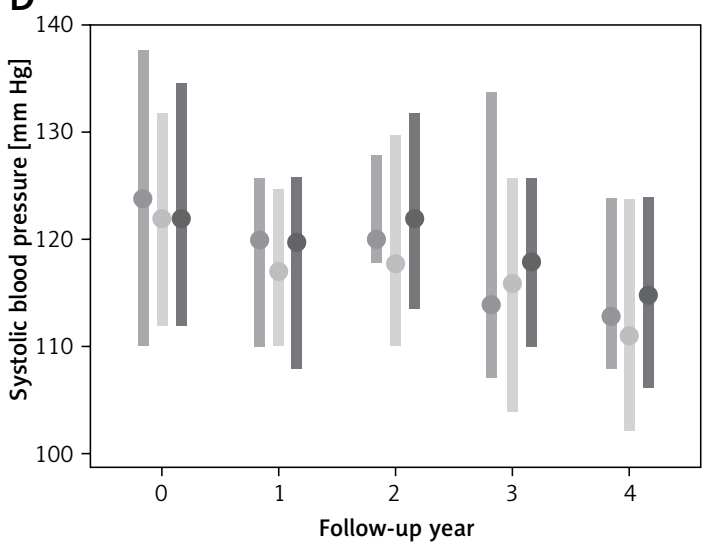

Statin plus niacin and ezetimibe

Figure 2. Effect of comprehensive cardiovascular disease risk management on longitudinal changes in plaque type and cIMT changes in a community-based prevention clinic 
A

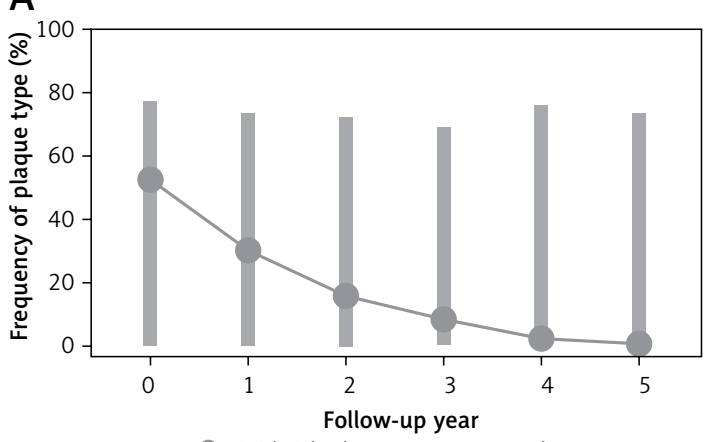

C

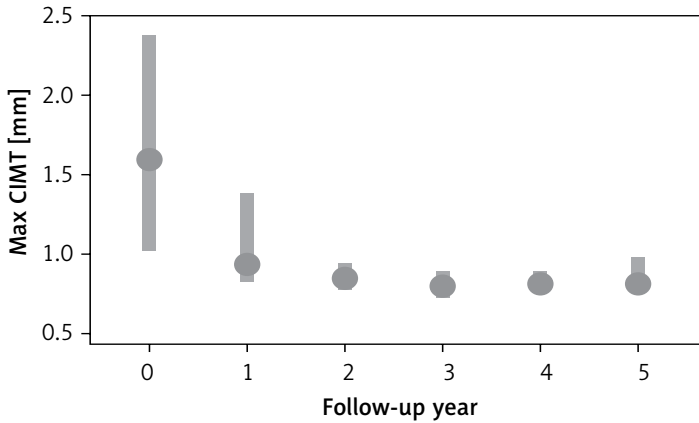

B

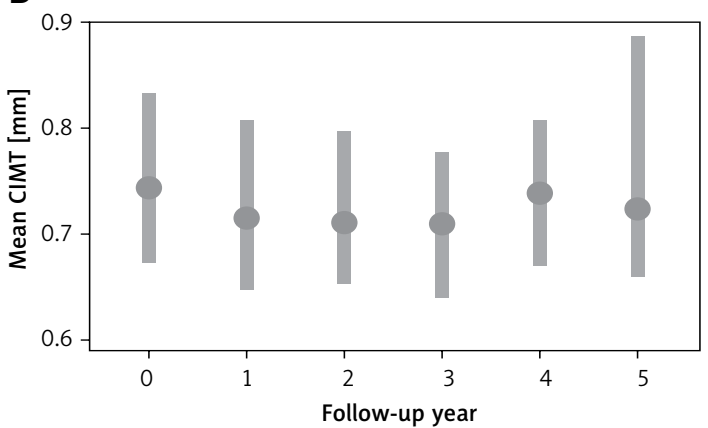

D

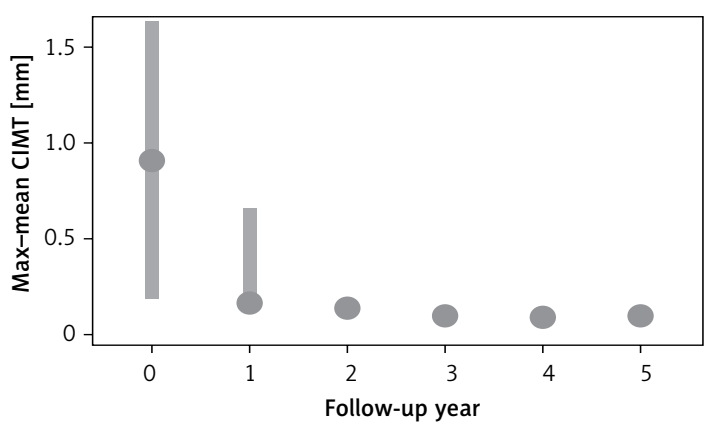

Figure 3. CIMT parameters over follow-up

Table III. CIMT over follow-up

\begin{tabular}{|c|c|c|c|c|c|c|c|c|}
\hline \multirow[t]{2}{*}{ Parameter } & \multicolumn{6}{|c|}{ Year } & \multirow{2}{*}{$\begin{array}{c}P \text {-value } \\
\text { (first year) }\end{array}$} & \multirow{2}{*}{$\begin{array}{l}P \text {-value (after } \\
\text { first year) }\end{array}$} \\
\hline & 0 & 1 & 2 & 3 & 4 & 5 & & \\
\hline$N(\%)$ & $\begin{array}{c}324 \\
(100)\end{array}$ & $\begin{array}{l}280 \\
(86)\end{array}$ & $\begin{array}{l}234 \\
(72)\end{array}$ & $\begin{array}{l}167 \\
(52)\end{array}$ & $\begin{array}{c}85 \\
(26)\end{array}$ & $\begin{array}{l}20 \\
(6)\end{array}$ & & \\
\hline Mean CIMT, mean \pm SD $[\mathrm{mm}]$ & $\begin{array}{c}0.77 \\
\pm 0.13\end{array}$ & $\begin{array}{c}0.73 \\
\pm 0.11\end{array}$ & $\begin{array}{c}0.74 \\
\pm 0.12\end{array}$ & $\begin{array}{c}0.73 \\
\pm 0.12\end{array}$ & $\begin{array}{c}0.75 \\
\pm 0.10\end{array}$ & $\begin{array}{c}0.78 \\
\pm 0.19\end{array}$ & $<0.001$ & $<0.001$ \\
\hline Max CIMT, mean $\pm \mathrm{SD}[\mathrm{mm}]$ & $\begin{array}{c}1.86 \\
\pm 1.04\end{array}$ & $\begin{array}{c}1.31 \\
\pm 0.86\end{array}$ & $\begin{array}{r}0.88 \\
\pm 0.15\end{array}$ & $\begin{array}{c}0.83 \\
\pm 0.14\end{array}$ & $\begin{array}{c}0.83 \\
\pm 0.11\end{array}$ & $\begin{array}{c}0.88 \\
\pm 0.20\end{array}$ & $<0.001$ & $<0.001$ \\
\hline $\begin{array}{l}\text { Max-mean CIMT, mean } \pm \text { SD } \\
{[\mathrm{mm}]}\end{array}$ & $\begin{array}{c}1.08 \\
\pm 1.00\end{array}$ & $\begin{array}{c}0.57 \\
\pm 0.84\end{array}$ & $\begin{array}{c}0.14 \\
\pm 0.45\end{array}$ & $\begin{array}{c}0.10 \\
\pm 0.04\end{array}$ & $\begin{array}{c}0.09 \\
\pm 0.03\end{array}$ & $\begin{array}{c}0.10 \\
\pm 0.03\end{array}$ & $<0.001$ & $<0.001$ \\
\hline Any plaque, $n(\%)$ & $\begin{array}{l}253 \\
(78)\end{array}$ & $\begin{array}{l}209 \\
(75)\end{array}$ & $\begin{array}{l}172 \\
(74)\end{array}$ & $\begin{array}{l}117 \\
(70)\end{array}$ & $\begin{array}{c}66 \\
(78)\end{array}$ & $\begin{array}{c}15 \\
(75)\end{array}$ & 0.076 & 0.448 \\
\hline Lipid-rich plaque, $n$ (\%) & $\begin{array}{l}172 \\
(53)\end{array}$ & $\begin{array}{c}85 \\
(30)\end{array}$ & $\begin{array}{c}37 \\
(16)\end{array}$ & $\begin{array}{l}14 \\
(8)\end{array}$ & $\begin{array}{c}2 \\
(2)\end{array}$ & $\begin{array}{c}0 \\
(0)\end{array}$ & $<0.001$ & $<0.001$ \\
\hline Heterogeneous plaque, $n(\%)$ & $\begin{array}{l}116 \\
(36)\end{array}$ & $\begin{array}{l}158 \\
(56)\end{array}$ & $\begin{array}{l}126 \\
(54) \\
\end{array}$ & $\begin{array}{c}85 \\
(51)\end{array}$ & $\begin{array}{c}50 \\
(59)\end{array}$ & $\begin{array}{c}10 \\
(50)\end{array}$ & $<0.001$ & 0.714 \\
\hline Calcified plaque, $n(\%)$ & $\begin{array}{c}56 \\
(17)\end{array}$ & $\begin{array}{c}80 \\
(29)\end{array}$ & $\begin{array}{c}91 \\
(39)\end{array}$ & $\begin{array}{c}63 \\
(38)\end{array}$ & $\begin{array}{c}35 \\
(41)\end{array}$ & $\begin{array}{c}8 \\
(40)\end{array}$ & $<0.001$ & 0.002 \\
\hline
\end{tabular}

\section{Discussion}

The aim of this study was to longitudinally evaluate the effect of comprehensive CVD risk intervention on subclinical carotid atherosclerosis. Using serial B-mode ultrasonography, we observed significant regression of CIMT (max, max-mean) and lipid-rich plaque. Previous CIMT studies using statin therapy alone showed reduction in CIMT progression, not regression [25-28,
30]. CIMT regression has been demonstrated in the setting of niacin monotherapy [29] as well as in comprehensive CVD risk reduction therapy, although the latter was confounded by patients receiving carotid endarterectomies [40]. Our study showed significant CIMT regression as well as regression of subclinical atherosclerotic plaque in response to a comprehensive treatment strategy with high prevalence of use of niacin in multiple drug combination therapy. 
Studies using high-resolution computed tomography, magnetic resonance imaging, and B-mode ultrasonography found that aggressive lipid-lowering therapies stabilize plaque by promoting delipidation of vulnerable plaque [32-34, $41,42]$. These studies correlated decreasing plaque lucency on ultrasound with decreased lipid content of plaque. Compared with CT, ultrasonography offers advantages in research and clinical settings through lower cost and absence of ionizing radiation exposure.

Our study expands on the previously published CIMT studies by including a comprehensive diet, lifestyle, and intensive, multiple drug pharmacological intervention. There was a robust decrease in lipid-rich plaque during the first 2 years of treatment followed by a steady decline at later time points. Delipidation of subclinical plaque was associated with reductions in LDL-C and non-HDL-C, and was best explained by the summary effects of comprehensive behavioral and dietary prevention interventions in combination with statin-based lipid-lowering regimens directed toward reduction in non-HDL-C and LDL-C to target levels.

There are several limitations to this study. As a retrospective study, we encountered issues with incomplete clinical data such as family history, obesity, and duration of baseline medication use, which could cause residual confounding. Another limitation was retrospective grouping of treatment groups, which can introduce bias if groups are incorrectly assigned. The study population was composed of a self-selected group of motivated Caucasian patients, which may impact the generalizability of this study. We modeled our study to examine yearly changes in CIMT, plaque, and lipids based on the study design of prior clinical trials. There may be long-term effects on CIMT and plaque composition beyond the duration of our study that may be revealed with a larger population size with longer follow-up.

In conclusion, this study examined multi-year CIMT and plaque changes in a cohort of patients receiving comprehensive CVD risk intervention. Using serial imaging, we observed a reduction of lipid-rich plaques with a concurrent increase in heterogeneous and calcific plaques, suggesting regression of lipidrich plaque or transformation into heterogeneous and calcified forms. We believe that understanding the progression of subclinical atherosclerosis will help shape our approach to CVD prevention. These results show the beneficial effect of comprehensive, evidence-based lipid management on subclinical atherosclerosis and vulnerable plaque.

\section{Acknowledgments}

This study did not receive any external funding. Dr. Martin is supported by the Pollin Cardiovascu- lar Prevention Fellowship and the Marie-Josée and Henry R. Kravis endowed fellowship.

\section{Conflict of interest}

Drs. Martin and Jones are listed as co-inventors on a pending patent filed by Johns Hopkins University for a method of low-density lipoprotein cholesterol estimation.

\section{References}

1. Brown BG, Bolson E, Frimer M, Dodge HT. Quantitative coronary arteriography: estimation of dimensions, hemodynamic resistance, and atheroma mass of coronary artery lesions using the arteriogram and digital computation. Circulation 1977; 55: 329-37.

2. Libby P, Ridker PM, Maseri A. Inflammation and atherosclerosis. Circulation 2002; 105: 1135-43.

3. Jaffer FA, O'Donnell CJ, Larson MG et al. Age and sex distribution of subclinical aortic atherosclerosis: a magnetic resonance imaging examination of the Framingham Heart Study. Arterioscler Thromb Vasc Biol 2002; 22: 849-54.

4. Lee TC, O'Malley PG, Feuerstein I, Taylor AJ. The prevalence and severity of coronary artery calcification on coronary artery computed tomography in black and white subjects. J Am Coll Cardiol 2003; 41: 39-44.

5. Salonen JT, Salonen R. Ultrasound B-mode imaging in observational studies of atherosclerotic progression. Circulation 1993; 87: II56-65.

6. Bond MG, Wilmoth SK, Enevold GL, Strickland HL. Detection and monitoring of asymptomatic atherosclerosis in clinical trials. Am J Med 1989; 86: 33-6.

7. Rubens J, Espeland MA, Ryu J, et al. Individual variation in susceptibility to extracranial carotid atherosclerosis. Arteriosclerosis 1988; 8: 389-97.

8. Dodani S, Dong L, Guirgis FW, Reddy ST. Carotid intima media thickness and low high-density lipoprotein (HDL) in South Asian immigrants: could dysfunctional HDL be the missing link? Arch Med Sci 2014; 10: 870-9.

9. Podgórski M, Grzelak P, Szymczyk K, Szymczyk E, Drożdż J, Stefańczyk L. Peripheral vascular stiffness, assessed with two-dimensional speckle tracking versus the degree of coronary artery calcification, evaluated by tomographic coronary artery calcification index. Arch Med Sci 2015; 11: 122-9.

10. Grobbee DE, Bots ML. Carotid artery intima-media thickness as an indicator of generalized atherosclerosis. J Intern Med 1994; 236: 567-73.

11. O'Leary DH, Polak JF, Kronmal RA, et al. Distribution and correlates of sonographically detected carotid artery disease in the Cardiovascular Health Study. The CHS Collaborative Research Group. Stroke 1992; 23: 1752-60.

12. O'Leary DH, Polak JF, Kronmal RA, Manolio TA, Burke GL, Wolfson SK Jr. Carotid-artery intima and media thickness as a risk factor for myocardial infarction and stroke in older adults. Cardiovascular Health Study Collaborative Research Group. N Engl J Med 1999; 340: 14-22.

13. O'Leary DH, Polak JF, Wolfson SK Jr, et al. Use of sonography to evaluate carotid atherosclerosis in the elderly. The Cardiovascular Health Study. CHS Collaborative Research Group. Stroke 1991; 22: 1155-63.

14. Salonen JT, Salonen R. Ultrasonographically assessed carotid morphology and the risk of coronary heart disease. Arterioscler Thromb 1991; 11: 1245-9. 
15. Selzer RH, Hodis HN, Kwong-Fu H, et al. Evaluation of computerized edge tracking for quantifying intima-media thickness of the common carotid artery from B-mode ultrasound images. Atherosclerosis 1994; 111: 1-11.

16. Bots ML, Breslau PJ, Briet E, et al. Cardiovascular determinants of carotid artery disease. The Rotterdam Elderly Study. Hypertension 1992; 19: 717-20.

17. Bots ML, Hoes AW, Koudstaal PJ, Hofman A, Grobbee DE. Common carotid intima-media thickness and risk of stroke and myocardial infarction: the Rotterdam Study. Circulation 1997; 96: 1432-7.

18. Chambless LE, Folsom AR, Clegg LX, et al. Carotid wall thickness is predictive of incident clinical stroke: the Atherosclerosis Risk in Communities (ARIC) study. Am J Epidemiol 2000; 151: 478-87.

19. Chambless LE, Heiss G, Folsom AR, et al. Association of coronary heart disease incidence with carotid arterial wall thickness and major risk factors: the Atherosclerosis Risk in Communities (ARIC) Study, 1987-1993. Am J Epidemiol 1997; 146: 483-94.

20. Sillesen H, Muntendam P, Adourian A, et al. Carotid plaque burden as a measure of subclinical atherosclerosis: comparison with other tests for subclinical arterial disease in the High Risk Plaque Biolmage study. JACC Cardiovasc Imaging 2012; 5: 681-9.

21. Stone NJ, Robinson J, Lichtenstein AH, et al. 2013 ACC/ AHA Guideline on the Treatment of Blood Cholesterol to Reduce Atherosclerotic Cardiovascular Risk in Adults: A Report of the American College of Cardiology/American Heart Association Task Force on Practice Guidelines. J Am Coll Cardiol 2013; S0735-1097: 06028-2.

22. Brown BG, Zhao XQ, Chait A, et al. Simvastatin and niacin, antioxidant vitamins, or the combination for the prevention of coronary disease. N Engl J Med 2001; 345: 1583-92.

23. Investigators AH, Boden WE, Probstfield JL, et al. Niacin in patients with low HDL cholesterol levels receiving intensive statin therapy. N Engl J Med 2011; 365: 2255-67.

24. Rubins HB, Robins SJ, Collins D, et al. Gemfibrozil for the secondary prevention of coronary heart disease in men with low levels of high-density lipoprotein cholesterol. Veterans Affairs High-Density Lipoprotein Cholesterol Intervention Trial Study Group. N Engl J Med 1999; 341: 410-8.

25. Byington RP, Furberg CD, Crouse JR 3rd, Espeland MA, Bond MG. Pravastatin, Lipids, and Atherosclerosis in the Carotid Arteries (PLAC-II). Am J Cardiol 1995; 76: 54C-9C.

26. Crouse JR 3rd, Byington RP, Bond MG, et al. Pravastatin, Lipids, and Atherosclerosis in the Carotid Arteries (PLAC-II). Am J Cardiol 1995; 75: 455-9.

27. Furberg CD, Adams HP Jr, Applegate WB, et al. Effect of lovastatin on early carotid atherosclerosis and cardiovascular events. Asymptomatic Carotid Artery Progression Study (ACAPS) Research Group. Circulation 1994; 90: 1679-87.

28. Furberg CD, Pitt B, Byington RP, Park JS, McGovern ME. Reduction in coronary events during treatment with pravastatin. PLAC I and PLAC II Investigators. Pravastatin Limitation of Atherosclerosis in the Coronary Arteries. Am J Cardiol 1995; 76: 60C-3C.

29. Villines TC, Stanek EJ, Devine PJ, et al. The ARBITER 6-HALTS Trial (Arterial Biology for the Investigation of the Treatment Effects of Reducing Cholesterol 6-HDL and LDL Treatment Strategies in Atherosclerosis): final results and the impact of medication adherence, dose, and treatment duration. J Am Coll Cardiol 2010; 55: 2721-6.
30. Crouse JR 3rd, Grobbee DE, O'Leary DH, et al. Measuring Effects on intima media Thickness: an Evaluation Of Rosuvastatin in subclinical atherosclerosis: the rationale and methodology of the METEOR study. Cardiovasc Drugs Ther 2004; 18: 231-8.

31. Crouse JR 3rd, Raichlen JS, Riley WA, et al. Effect of rosuvastatin on progression of carotid intima-media thickness in low-risk individuals with subclinical atherosclerosis: the METEOR Trial. JAMA 2007; 297: 1344-53.

32. Nissen SE. Effect of intensive lipid lowering on progression of coronary atherosclerosis: evidence for an early benefit from the Reversal of Atherosclerosis with Aggressive Lipid Lowering (REVERSAL) trial. Am J Cardiol 2005; 96: 61F-8F.

33. Kadoglou NP, Sailer N, Moumtzouoglou A, Kapelouzou A, Gerasimidis T, Liapis CD. Aggressive lipid-lowering is more effective than moderate lipid-lowering treatment in carotid plaque stabilization. J Vasc Surg 2010; 51: 114-21.

34. Hattori K, Ozaki Y, Ismail TF, et al. Impact of statin therapy on plaque characteristics as assessed by serial OCT, grayscale and integrated backscatter-IVUS. JACC Cardiovasc Imaging 2012; 5: 169-77.

35. National Cholesterol Education Program Expert Panel on Detection E, Treatment of High Blood Cholesterol in A. Third Report of the National Cholesterol Education Program (NCEP) Expert Panel on Detection, Evaluation, and Treatment of High Blood Cholesterol in Adults (Adult Treatment Panel III) final report. Circulation 2002; 106: 3143-421.

36. Banach M, Aronow WS, Serban C, et al. Lipids, blood pressure and kidney update 2014. Pharmacol Res 2015; 95-97C: 111-25.

37. Banach M, Rizzo M, Toth PP, et al. Statin intolerance an attempt at a unified definition. Position paper from International Lipid Expert Panel. Arch Med Sci 2015; 11 : 1-23.

38. Friedewald WT, Levy RI, Fredrickson DS. Estimation of the concentration of low-density lipoprotein cholesterol in plasma, without use of the preparative ultracentrifuge. Clin Chem 1972; 36: 499-504.

39. Den Ruijter HM, Peters SA, Anderson TJ, et al. Common carotid intima-media thickness measurements in cardiovascular risk prediction: a meta-analysis. JAMA 2012; 308: 796-803.

40. Spence JD, Eliasziw M, DiCicco M, et al. Carotid plaque area, a tool for targeting and evaluating vascular preventive therapy. Stroke 2002; 33: 2916-22.

41. Burgstahler C, Reimann A, Beck T, et al. Imaging of a regressive coronary soft plaque under lipid lowering therapy by multi-slice computed tomography. Int J Cardiovasc Imaging 2006; 22: 119-21.

42. Lee JM, Robson MD, Yu LM, et al. Effect of high-dose modified-release nicotinic acid on athersclerosis and vascular function: a randomized placebo-controlled, magnetic resonance imaging study. J Am Coll Cardiol 2009; 54: 1787-94. 